\title{
Mineralogical Variability of Fly Ashes Classified by Electrostatic Precipitator
}

\author{
Seung Heun LEE, Ki Dong KIM, Etsuo SAKAI* and Masaki DAIMON* \\ Faculty of Materials \& Chemical Engineering, Kunsan National University, San 68, Miryong-dong, Kunsan 573-701 Korea \\ *Department of Metallurgy and Ceramic Science, Graduate School, Tokyo Institute of Technology, \\ 2-12-1, Ookayama, Meguro-ku, Tokyo 152-8552
}

\section{電気集じん機により段別採取したフライアッシュの鉱物組成の変化 李 昇憲·金 基東·坂井悦郎*·大門正機* \\ 群山大学校材料·化学工学部, 573-701 大韓民国群山市米龍洞山 68 \\ *東京工業大学大学院理工学研究科, 152-8552 東京都目黒区大岡山 2-12-1}

\begin{abstract}
The mineralogical compositions of bituminous fly ashes varied depending on the locations of hoppers attached to an electrostatic precipitator in coal-fired power plant. From the first hopper towards the third hopper, that is, as the particles of fly ashes decreased in size, the content of glassy phase increased, while the amount of $\alpha$-quartz decreased. When the boiler was operated at full load in comparison with operating at half load, the content of glassy phase was greater. The chemical compositions of the glassy phase showed a tendency in $\mathrm{Al}_{2} \mathrm{O}_{3}$ increase, while $\mathrm{SiO}_{2}$ decreased as the particles size became smaller.
\end{abstract}

[Received June 6, 2002; Accepted November 6, 2002]

Key-words : Fly ash, Electrostatic precipitator, Mineralogical composition, Glassy phase

\section{Introduction}

Coal-fired power plants which have recently constructed to resolve the current energy supplying problem will discharge a large amount of fly ashes, making it difficult to secure a filled-in land. It is thus very important to utilize more fly ashes in terms of recycling resources. However, there are some problems in recycling fly ashes due to their various qualities depending on the coal compositions, combustion conditions etc. To resolve this situation, in the coal-fired power plants the collected fly ashes are classified by air separator in accordance with the specifications or needs. In this method, a silo stores the fly ashes already classified in the hoppers attached to an electrostatic precipitator. The stored fly ashes in silo are classified again to needed amount with aid of classifier. In our previous works ${ }^{1), 2}$ the function of an electrostatic precipitator as classifier was reported, and for the purpose of a reliable use of high quality fly ashes it was suggested that the fly ashes collected by hoppers attached to an electric precipitator could be used as a mineral admixture in accordance with their properties.

Fly ashes reacting with calcium hydroxide at room temperature can act pozzolanic materials. Since their pozzolanic activity is attributable to the presence of $\mathrm{SiO}_{2}$ and $\mathrm{Al}_{2} \mathrm{O}_{3}$ in the glassy phase existing in fly ashes, ${ }^{3)}$ it is very important for the examination of the pozzolanic activity of fly ashes to know the amount and chemical composition of the glassy phase in them. Joshi and Rosaver ${ }^{4}$ could examine the amounts of $\mathrm{SiO}_{2}$ and $\mathrm{Al}_{2} \mathrm{O}_{3}$ in fly ashes by dissolving them into hydrogen fluoride. Sersale ${ }^{5}$ classified the activity levels of fly ashes by calculating the soluble $\mathrm{SiO}_{2}$ with aid of chemical analysis. However, these wet analyses do not yield exact amount and composition of the glassy phase in fly ashes because a part of crystalline phases is dissolved together and only specific components can be quantified.

The studies ${ }^{6), 7)}$ on mineralogical composition of fly ashes by X-ray diffraction analysis have been centered on the Western Fly Ash Research and Development Center (WFARDC) in the University of North Dakota in North America, where the crystalline phases of the various fly ashes from the United States and Canada have been quantified by using $\mathrm{TiO}_{2}$ as an internal standard. Coal-fired power plants in North American area using many type of coal generate various classes of fly ashes. Semi-quantitative X-ray diffraction analysis has been applied to quantify minerals in fly ashes because convenience and rapidity are required rather than accuracy. Having quantified the glassy and crystalline phases of fly ashes from Japan using $\mathrm{ZnO}$ as an internal standard, Nagataki et al. ${ }^{8)}$ have used it to evaluate the quality of fly ashes. Being semi-quantitative, these methods cannot make it possible to determine the base line exactly because of the background elevation due to the glassy phase, nor the exact peak intensity measurement due to the matrix effect. Roode et al. ${ }^{9)}$ presented the feasibility for quantifying crystalline phases in the mixtures of glassy cordierite and $\alpha$-cordierite crystalline polymorph with X-ray diffraction using $\mathrm{NaCl}$ as an internal standard. Based on those results, they determined the glass content in fly ashes and slags by using glass as dilute matter and $\mathrm{CaF}_{2}$ as an internal standard.

The purpose of this paper is to investigate the variability of the mineralogical compositions of fly ashes according to the position of hoppers attached to an electrostatic precipitator in a coal-fired power plant using quantitative X-ray diffraction analysis.

\section{Experimental procedures}

\subsection{Fly ashes}

Fly ashes used in the experiment were from a coal-fired power plant in Japan. The fly ashes were collected from a hopper attached to an electrostatic precipitator after changing the burning condition and the type of bituminous coal. A series is the fly ash generated when the load of the boiler was $600 \mathrm{MW}$, while $\mathrm{A}^{\prime}$ series is the collected fly ash when the load of the boiler was $300 \mathrm{MW}$ (at night) with the same type of coal used for A series. B series is the fly ash when a different bituminous coal was used under the same load (600 MW) as A series. As shown in Fig. 1, the electrostatic precipitator has three hoppers in the direction of flue gas exhaustion. Fly ashes collected from the hopper closest to the inlet were named $\mathrm{A}-1, \mathrm{~A}^{\prime}-1$ and $\mathrm{B}-1$. Fly ashes collected from the second hopper were named $\mathrm{A}-2, \mathrm{~A}^{\prime}-2$ and $\mathrm{B}-2$. Finally, fly ashes collected from the hopper located at the out- 


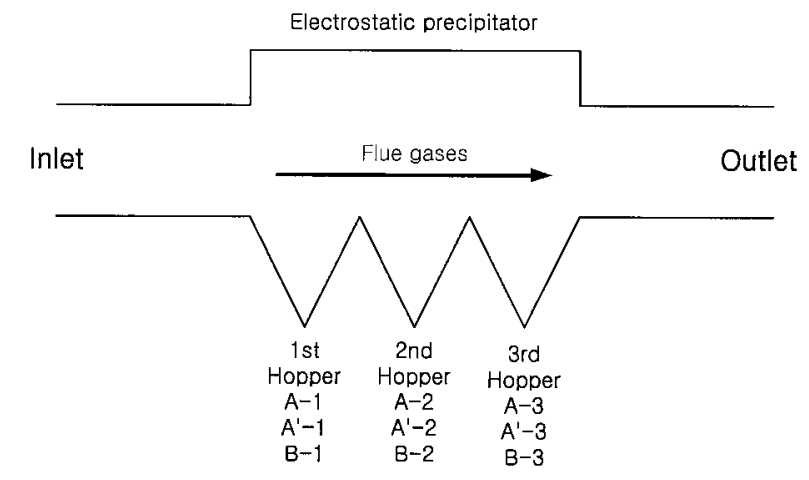

Fig. 1. Collected hoppers of the electrostatic precipitator in the coal-fired power plant.

let were named $\mathrm{A}-3, \mathrm{~A}^{\prime}-3$ and $\mathrm{B}-3$.

Chemical analysis of fly ashes was carried out using an atomic absorption spectrophotometer (Shimadzu Co., AA680 , Japan). Carbon content was determined by carbon analyzer (Horiba Co., Chromatic-C, Japan) and loss on ignition was done following JIS A 6201. Mean particle size of fly ashes was measured by a laser diffraction method (Microtrack-9320 HRA, USA). Measurement of Blaine value was performed according to JIS R 5201.

2.2 Quantitative X-ray diffraction analysis of fly ashes

\subsubsection{Internal standard method}

The quantitative analysis by X-ray powder diffraction is expressed by Alexander and Klug's principle ${ }^{10)}$ as follows,

$$
I_{\mathrm{A}}=K_{\mathrm{A}} \cdot W_{\mathrm{A}} / \rho_{\mathrm{m}} \cdot \mu_{\mathrm{m}}
$$

where $I_{\mathrm{A}}$ is the diffraction intensity on the specific plane of the crystalline phase $\mathrm{A}$ in the powder mixtures, $W_{\mathrm{A}}$ is the mass fraction of crystalline phase $\mathrm{A}$ in the powder mixtures, $K_{\mathrm{A}}$ is a constant, $\rho_{\mathrm{m}}$ is the density of the mixture and $\mu_{\mathrm{m}}$ is the mass absorption coefficient. When an internal standard is used, the Eq. (1) is converted as follows,

$$
I_{\mathrm{A}} / I_{\mathrm{S}}=K_{\mathrm{A}} / K_{\mathrm{S}} \cdot W_{\mathrm{P}} / W_{\mathrm{S}}=K \cdot W_{\mathrm{P}} / W_{\mathrm{S}}
$$

where $I_{\mathrm{S}}$ and $W_{\mathrm{S}}$ are the diffraction intensity and the mass fraction of the added internal standard, respectively, and $K_{\mathrm{S}}$ and $K$ are constants. The above equation, where the mass absorption coefficient $\left(\mu_{\mathrm{m}}\right)$ is canceled out, represents the correlation between the mass fraction and the ratio of diffraction intensities. In other words, the ratio between diffraction intensities of crystalline phase $\mathrm{A}$ and internal standard $\mathrm{S}$ is linearly proportional to the ratio between mass fractions of crystalline phase A and internal standard S. In this experiment, standard curves were prepared based on the Eq. (2).

\subsubsection{Selection of an internal standard and matrix}

When specific crystalline phases in the mixture are being quantified with X-ray powder diffraction, the quantitative values are affected by the mass absorption coefficient of the components that are not quantified. Under consideration of this problem, the silicate glass was used as a matrix whose main component is $\mathrm{SiO}_{2}\left(71.5 \mathrm{SiO}_{2}, 11.5 \mathrm{Na}_{2} \mathrm{O}, 11.0 \mathrm{CaO}\right.$, $2.0 \mathrm{Al}_{2} \mathrm{O}_{3}, 4.0$ others, mass $\left.\%\right)$. The reason why silicate glass was used as a matrix is that not only its halo is similar to that of fly ashes used in this experiment but also it is easily obtainable. Strictly speaking, however, the bulk chemical composition of fly ash glasses depends on fly ashes itself. Therefore, the glassy phase with the same chemical composition as each fly ash glass should be used as a matrix for the precise measurement. It is, however, not easy to obtain the glass with the same chemical composition as fly ash glass directly, and it is also complicated to obtain a standard curve with different matrix for each quantitative analysis. $\mathrm{CaF}_{2}$ of the reagent grade was used as an internal standard, which is not hygroscopicity and does not overlap the diffraction lines of crystalline phases in the fly ashes.

2.2.3 Sample preparation for standard curves

The X-ray diffraction pattern showed that the major crystalline phases were $\alpha$-quartz and mullite, and the minor phases were magnetite, hematite and lime. Based on this results, the standard curves for the corresponding peaks were prepared. The $\alpha$-quartz, hematite, magnetite and $\mathrm{CaF}_{2}$ used were the reagent grade. The high purity sintered material was used for the mullite. And the lime used was reagent grade $\mathrm{CaCO}_{3}$ treated thermally at $1000^{\circ} \mathrm{C}$ for $4 \mathrm{~h}$. In a vibration mill these samples were milled less than $10 \mu \mathrm{m}$ in size in order to reduce the deviation in diffraction intensity.

The fractions of samples in the mixture for preparing the standard curves were 5-50 mass $\%$ for $\alpha$-quartz, mullite, and 0.3-3.0 mass \% for hematite, magnetite and lime. 20 mass\% of $\mathrm{CaF}_{2}$ were added to these mixtures. All the samples were mixed that is reported as optimal time by Hagino et al. ${ }^{11)}$ in a wet system.

2.2.4 Conditions for X-ray powder diffraction analysis An X-ray diffractometer (Mac Science Co., Japan) with $\mathrm{Cu}$ target, operated at $40 \mathrm{kV}$ and $30 \mathrm{~mA}$, was used. The width of divergence slit was $1^{\circ}$ and the receiving slit was 0.3 $\mathrm{mm}$ with graphite monochrometer. As scanning condition, step scanning was performed with $0.02^{\circ}$ and the preset time of $20 \mathrm{~s}$.

\subsubsection{Preparation of standard curves}

After being weighed of $5 \mathrm{~g}$, the batching sample was filled into the aluminum holder manually under the constant pressure on the flat rubber plate in order to eliminate the preferred orientation. The peaks used for the quantitative analysis are represented in Table 1 . Scanning range was $1.64^{\circ}(2 \theta)$ for one peak. For minor phases as hematite, magnetite and lime, their weak peaks make it difficult to determine the base line and peak line. Therefore, the program in the instrument was used to accomplish smoothing.

The detection limit for quantitative analysis was set to be 0.3 mass \%. It is difficult to measure the base line for fly ashes exactly with the software in the instrument because elevation of the background occurs due to glassy phase in fly ash. The base line was thus determined manually. The area between the base line and the peak line was taken to be the peak intensity. Each result was tested three times and the averaged value was taken. The coefficient of variation that provides the error in preparing standard curves lay in $2.0-3.0 \%$. By placing the mass $\%$ of the quantified material to the vertical axis, and the intensity ratio between that material and the standard to the horizontal axis, standard curves were obtained with aid of the least square method. The standard curves for $\alpha$-quartz and hematite are presented in Fig. 2.

2.2.6 Quantitative determination of crystalline phases and glassy phase

The inner part of some fly ash particles consists of crystalline phase, and its outer side consists of glassy phase. So, the X-ray intensity arrived at crystalline phase, which is located inside, tends to weaker since the X-ray is partially absorbed into the outer side glassy phase. The large fly ash particle is getting, the more it shows this tendency. To exclude this influence, the fly ashes were milled less than 10 $\mu \mathrm{m}$ in a vibration mill.

20 mass $\%$ of $\mathrm{CaF}_{2}$ were added to the fly ash powder below $10 \mu \mathrm{m}$, and they were mixed by the same method as preparation of standard curves. Also, the intensity ratio of the quantified material to $\mathrm{CaF}_{2}$ was obtained by X-ray diffraction analysis under the same conditions as the stan- 
Table 1. X-Ray Diffraction Peaks Scanned for Quantitative Analysis

\begin{tabular}{ccc}
\hline Phases & $\mathbf{2 \theta}$ & $\mathbf{2 \theta}$ range scanned \\
\hline CaF2 & 28.3 & $27.47-29.13$ \\
$\alpha$-quartz & 20.8 & $20.00-21.66$ \\
Mullite & 16.4 & $15.57-17.23$ \\
Hematite & 24.1 & $23.27-24.93$ \\
Magnetite & 30.1 & $29.27-30.93$ \\
Lime & 32.4 & $31.60-33.26$ \\
\hline
\end{tabular}
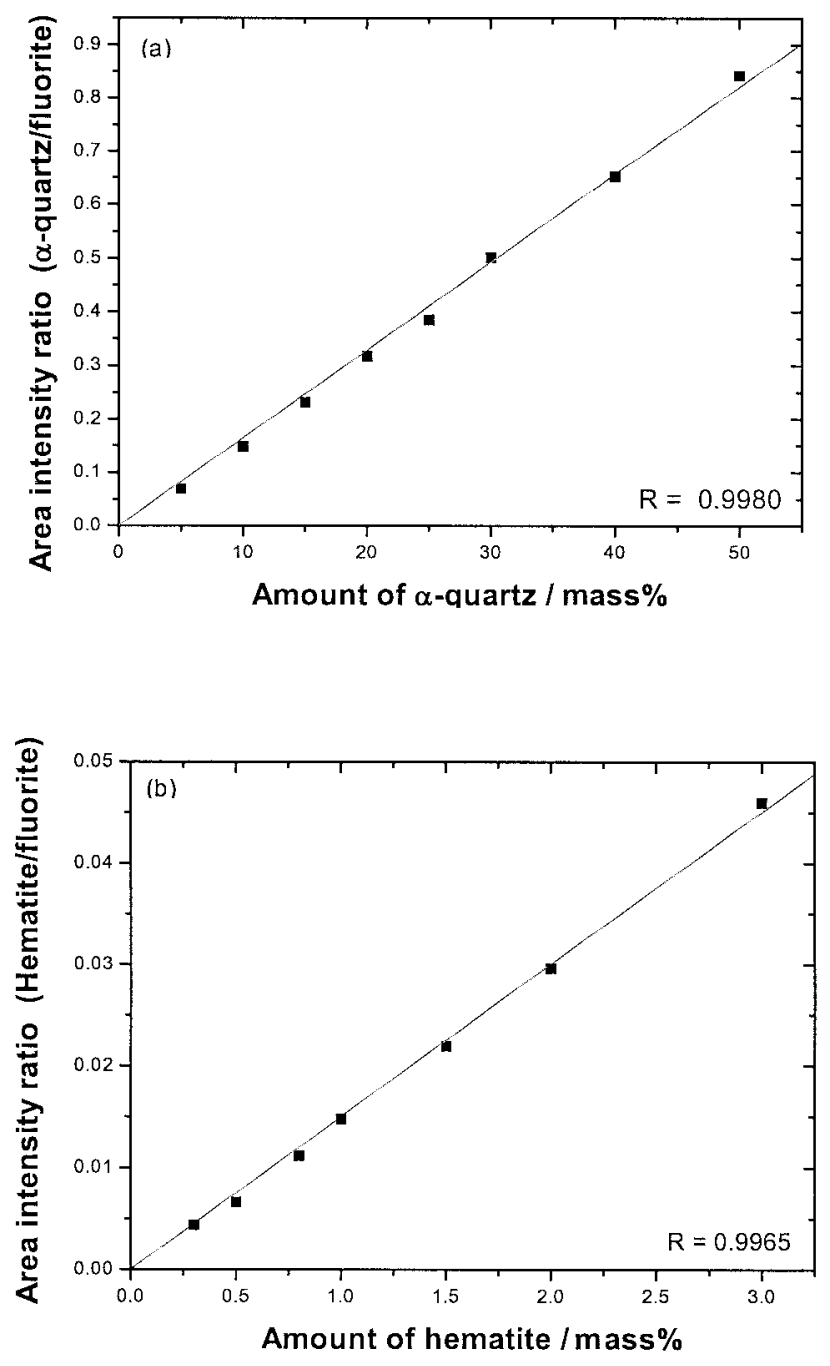

Fig. 2. Standard curves for $\alpha$-quartz (a) and hematite (b).

dard curves. Mullite, hematite, magnetite and lime were quantified from each standard curve. Three measurements per each samples were performed to obtain an average value. For anhydrite, a peak was shown at $2 \theta=25.4^{\circ}$, but it was determined by calculation because it was very weak and overlapped by that of mullite. The calculation was performed under the assumption that $\mathrm{SO}_{3}$ component in fly ashes exists in anhydrite form although a part of that dissolves in alkali sulphates and glassy phase. The amount of glassy phase was obtained by subtracting the amount of crystalline phases and the loss on ignition from 100 mass\%.

\section{Results and discussion}

The physical properties of fly ashes summarized in
Table 2 show that regardless of the burning condition and the coal type, the Blaine value and the density of the fly ashes increase from the first hopper toward the third one. The mean particle size of the fly ashes was more than $28 \mu \mathrm{m}$ in the first field, but it lay between 3.8 and $6.9 \mu \mathrm{m}$ in the third one.

The chemical composition of the fly ashes is represented in Table 3. Carbon content was the least in case of the third hopper with the smallest mean particle size, but the loss on ignition had no such relationship. The total amount of $\mathrm{SiO}_{2}$ and $\mathrm{Al}_{2} \mathrm{O}_{3}$ was over 80 mass $\%$ for $\mathrm{A}$ and $\mathrm{A}^{\prime}$ series, and 75 mass $\%$ for $B$ series. They showed a composition of the typical bituminous coal ashes. The chemical composition of fly ashes was dependent on the collection site, $\mathrm{SiO}_{2}$ decreased from the first hopper towards the third hopper. However, $\mathrm{Al}_{2} \mathrm{O}_{3}$ increased slightly. The total amount of $\mathrm{Fe}_{2} \mathrm{O}_{3}$, the alkali and alkali earth oxides, which lowered the melting temperature of fly ashes, was around 10 mass $\%$ for $\mathrm{A}$ and $\mathrm{A}^{\prime}$ series, and 13 mass $\%$ for $\mathrm{B}$ series. It showed a slight increasing tendency from the first hopper towards the third hopper. There was little difference in chemical composition according to the burning condition. But, the chemical composition of fly ashes was affected by the coal type. The amount of $\mathrm{CaO}$ for $\mathrm{B}$ series was 7.5-8.1 mass\%, being approximately three times as $\mathrm{A}, \mathrm{A}^{\prime}$ series. There was also much amount of $\mathrm{SO}_{3}$.

The results of X-ray diffraction for fly ashes are represented in Fig. 3. Regardless of the coal type and the collection site, the major crystalline phases were mullite and $\alpha$-quartz, and the minor ones were magnetite, hematite and anhydrite. For B series which contained a large amount of $\mathrm{CaO}$ component, the peak of lime was shown.

Figure 4 shows the mineralogical compositions quantified by the X-ray powder diffraction. The glassy phase content of $\mathrm{A}$ and $\mathrm{A}^{\prime}$ series was between $65.9-76.8$ mass $\%$, increased from the first hopper towards the third hopper. The increased amount was 6.2 mass $\%$ for $600 \mathrm{MW}$, and 8.2 mass $\%$ for $300 \mathrm{MW}$. It means that the finer the particles of fly ashes are, the greater the glassy phase content becomes. On the other hand, the amount of $\alpha$-quartz decreased towards the third hopper. Although exhibiting the similar tendency, B series contained half mullite but more glass content comparing with $\mathrm{A}$ and $\mathrm{A}^{\prime}$ series. It contained $1.3-2.0$ mass $\%$ of new phase, lime.

The content of glassy phase depends on the cooling rate of melt. ${ }^{3)}$ Higher cooling rate restrains the precipitation of the crystalline phase. As a result the content of glassy phase would increase. While the pulverized coal goes through the combustion process in the boiler, where the temperature of the boiler frame is over $1600^{\circ} \mathrm{C}$, inorganic materials would melt except some minerals. The melt is converted into molten particles with spherical form by the surface tension. ${ }^{3)}$ These molten particles flow off the boiler as they move and cool down by gases such as $\mathrm{CO}_{2}, \mathrm{H}_{2} \mathrm{O}$ generated during combustion. The minimum fluidizing velocities and moving velocities of molten particles depend largely on their diameters instead of densities. ${ }^{12)}$ Therefore, smaller parti- 
Table 2. Physical Property of Fly Ashes Classified by Electrostatic Precipitator

\begin{tabular}{cccc}
\hline Fly ash & Density $\left(\mathbf{g} / \mathbf{c m}^{3}\right)$ & Surface area $\left(\mathbf{c m}^{2} / \mathbf{g}\right)$ & Mean particle size (/m) \\
\hline A-1 & 2.06 & 2760 & 34.6 \\
A-2 & 2.22 & 4180 & 18.6 \\
A-3 & 2.42 & 7360 & 6.9 \\
A'-1 & 2.08 & 3580 & 30.4 \\
A'-2 & 2.23 & 4980 & 15.6 \\
A'-3 & 2.40 & 7920 & 6.9 \\
B-1 & 2.24 & 2640 & 28.1 \\
B-2 & 2.33 & 4490 & 12.5 \\
B-3 & 2.48 & 7290 & 3.8 \\
\hline
\end{tabular}

Table 3. Chemical Composition of Fly Ashes Classified by Electrostatic Precipitator

\begin{tabular}{|c|c|c|c|c|c|c|c|c|c|c|}
\hline Fly ash & $\mathrm{SiO}_{2}$ & $\mathbf{A l}_{2} \mathbf{O}_{3}$ & $\mathrm{Fe}_{2} \mathrm{O}_{3}$ & $\mathrm{CaO}$ & $\mathrm{MgO}$ & $\mathrm{SO}_{3}$ & $\mathrm{Na}_{2} \mathrm{O}$ & $\mathbf{K}_{2} \mathbf{O}$ & $\mathrm{C}$ & Ig. loss \\
\hline A-1 & 63.8 & 24.8 & 4.6 & 2.3 & 0.9 & 0.3 & 1.2 & 0.7 & 0.7 & 1.1 \\
\hline$A-2$ & 62.0 & 25.5 & 4.3 & 2.2 & 1.2 & 0.4 & 1.3 & 0.8 & 0.8 & 1.2 \\
\hline A-3 & 59.5 & 26.4 & 4.8 & 2.3 & 1.2 & 1.0 & 1.3 & 0.8 & 0.3 & 1.7 \\
\hline$A^{\prime}-1$ & 62.5 & 24.9 & 4.2 & 2.0 & 1.1 & 0.5 & 1.2 & 0.8 & 1.5 & 2.1 \\
\hline$A^{\prime}-2$ & 60.9 & 25.4 & 4.5 & 2.3 & 0.9 & 0.6 & 1.2 & 0.8 & 1.3 & 2.1 \\
\hline$A^{\prime}-3$ & 59.6 & 26.4 & 4.3 & 2.3 & 1.1 & 1.0 & 1.4 & 0.8 & 0.4 & 1.9 \\
\hline B-1 & 61.9 & 18.2 & 5.5 & 7.5 & 2.2 & 0.6 & 1.6 & 0.6 & 1.0 & 1.0 \\
\hline B-2 & 58.5 & 20.3 & 5.1 & 8.1 & 2.4 & 0.8 & 1.9 & 0.7 & 1.1 & 1.1 \\
\hline B-3 & 55.7 & 22.0 & 5.7 & 7.9 & 2.2 & 1.4 & 2.1 & 0.7 & 0.5 & 0.5 \\
\hline
\end{tabular}

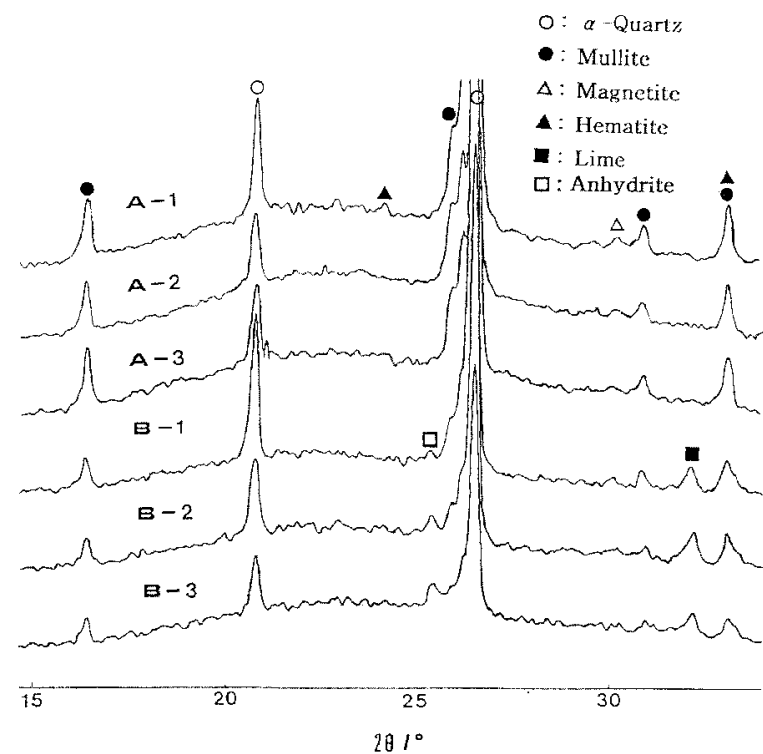

Fig. 3. XRD patterns of fly ashes classified by electrostatic precipitator.

cles with greater minimum fluidizing velocities and moving velocities cool down more rapidly. It is expected that the fly ashes in the third hopper consisting of fine particles would contain a large amount of glassy phase as shown in Fig. 4.

A part of $\alpha$-quartz in pulverized coal participates to form glass and the remainder exists in ashes. Eroded $\alpha$-quartz in the combustion process is in angular shape, which has larger particle size than that of spherical shape. ${ }^{13)}$ As a result, the fly ashes consisting of large particles in the first hopper contain a large amount of $\alpha$-quartz. Mullite is crystallized unlike $\alpha$-quartz when the molten ashes cooled down, although it is formed in part by the decomposition of the clay minerals in the original coal. The amount of mullite depends on the cool-

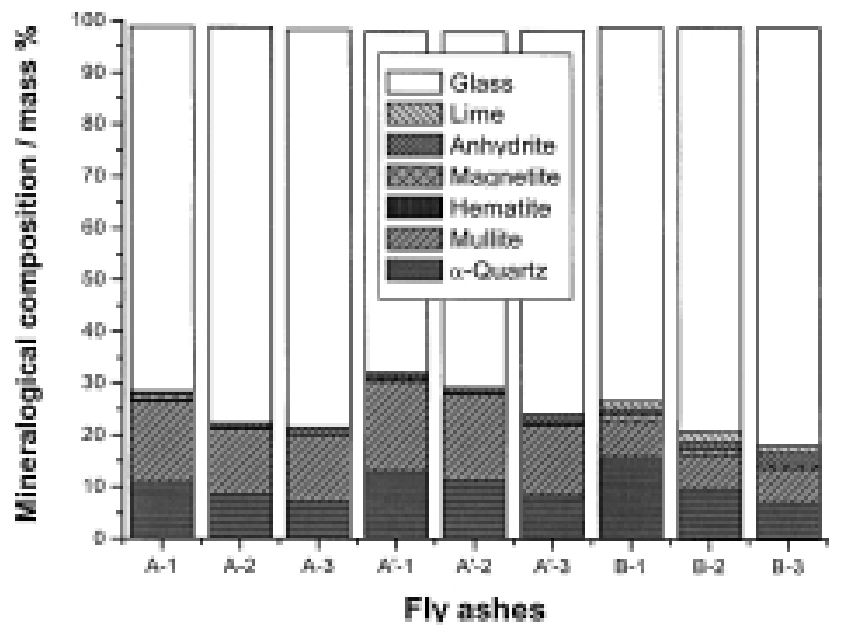

Fig. 4. Mineralogical composition of fly ashes classified by electrostatic precipitator.

ing rate and the chemical composition of melt. ${ }^{13)}$ The chemical composition of fly ashes indicates more amount of $\mathrm{Al}_{2} \mathrm{O}_{3}$ towards the third hopper. According to the phase diagram of $\mathrm{SiO}_{2}-\mathrm{Al}_{2} \mathrm{O}_{3},{ }^{14)}$ the fly ashes collected from the third hopper could contain more mullite. But, this is different from the quantitative result for minerals, indicating that the cooling rate is the determining factor instead of the melt composition.

Fly ashes collected from the same hopper had more amount of glassy phase at full load of $600 \mathrm{MW}$ than at half load of $300 \mathrm{MW}$. This may be caused by the instability of combustion state due to the decreasing load of boiler.

As shown in the quantitative results, fly ashes contained a substantial amount of glassy phase and showed a halo due to the glassy phase. This halo indicates that the structure has no long range order. As network modifiers alkali 
Table 4. Chemical Composition of Glassy Phase in Fly Ashes Classified by Electrostatic Precipitator

\begin{tabular}{|c|c|c|c|c|c|}
\hline Fly ash & $\mathrm{SiO}_{2}$ & $\mathrm{Al}_{2} \mathrm{O}_{3}$ & $\mathrm{Fe}_{2} \mathrm{O}_{3}$ & $\Sigma(\mathrm{CaO}+\mathrm{MgO})$ & $\sum\left(\mathrm{Na}_{2} \mathrm{O}+\mathrm{K}_{2} \mathrm{O}\right)$ \\
\hline$A-1$ & 68 & 20 & 5 & 4 & 3 \\
\hline$A-2$ & 65 & 22 & 5 & 4 & 3 \\
\hline A-3 & 63 & 23 & 6 & 4 & 3 \\
\hline$A^{\prime}-1$ & 67 & 19 & 5 & 5 & 4 \\
\hline$A^{\prime}-2$ & 65 & 20 & 6 & 4 & 4 \\
\hline$A^{\prime}-3$ & 64 & 23 & 5 & 4 & 3 \\
\hline B-1 & 61 & 18 & 6 & 12 & 3 \\
\hline B-2 & 60 & 20 & 5 & 11 & 3 \\
\hline B-3 & 58 & 21 & 6 & 11 & 4 \\
\hline
\end{tabular}

and alkali earth oxides weaken the glass-network by production of non-bridging oxygen that makes the structure more disordered.3) Also, as the amount of network modifier increases, the structure becomes more disordered. This makes the maximum position of halo shift toward a higher angle. ${ }^{15)}$ The halo taken from $\mathrm{X}$-ray diffraction analysis shows the maximum value at $2 \theta=23.5^{\circ}$ regardless of the collection place, the burning condition and the coal type. Therefore, the structure of fly ash glasses may not differ considerably.

Under the assumption that the crystalline phases have stoichiometric composition, it could be determined the chemical composition of glassy phase by subtracting the composition of crystalline phases from that of fly ashes. However the chemical composition of glassy phase is expressed double figures by considering error because it is somewhat irrelevant to apply stoichiometric composition as for mullite and magnetite. The chemical composition of the glassy phase is represented in Table 4. The glassy phase was largely composed of $\mathrm{SiO}_{2}(58-68$ mass\%) which can form a network, and of $\mathrm{Al}_{2} \mathrm{O}_{3}(18-23$ mass \%) as an intermediate oxide. The total amount of network modifier was less than 10 mass \% for A and $\mathrm{A}^{\prime}$ series, but $14-15$ mass $\%$ for $\mathrm{B}$ series containing much $\mathrm{CaO}$. Also, the molar ratio of $\mathrm{Al} /(\mathrm{Si}+\mathrm{Al})$ in glassy phase increased from 0.25 at the first hopper to 0.30 at the third hopper regardless of the coal type and the burning condition. In other words, as the particles became finer, the amount of $\mathrm{Al}_{2} \mathrm{O}_{3}$ increased while that of $\mathrm{SiO}_{2}$ decreased. The glassy phase in fly ashes belongs to aluminoslicate system because it contains $\mathrm{SiO}_{2}$ and $\mathrm{Al}_{2} \mathrm{O}_{3}$ as major components for both $\mathrm{A}$ and $\mathrm{B}$ series.

Also, the smaller particles for both series are accompanied by slight decrease of the $\mathrm{SiO}_{2}$ content along with slight increase of the $\mathrm{Al}_{2} \mathrm{O}_{3}$ from approximately 18 mass $\%$ to 23 mass \%. According to the phase diagram of $\mathrm{SiO}_{2}-\mathrm{Al}_{2} \mathrm{O}_{3}$, the liquidus temperature increases as the content of $\mathrm{Al}_{2} \mathrm{O}_{3}$ increases in this range. ${ }^{14)}$ However once melted, the surface tension of the melt increases. ${ }^{16)}$ Therefore, the sphericity of the fine molten ashes will increase during the cooling process comparing with that of the large molten ashes.

\section{Conclusions}

In the present work, it was examined the mineralogical variability of bituminous fly ashes classified by electrostatic precipitator using quantitative X-ray diffraction analysis. Based on the experimental results, it can be concluded as follows.

(1) The mineralogical composition of the fly ashes de- pended on the type of coal and the position of the hopper in the electrostatic precipitator. And, from the first hopper toward the third hopper, the particle size of fly ashes decreased, the content of glassy phase increased while the content of $\alpha$-quartz decreased.

(2) Fly ashes collected from the same hopper had more amount of glassy phase at full load of $600 \mathrm{MW}$ than at half load of $300 \mathrm{MW}$ in the boiler running condition.

(3) The glassy phase in fly ashes was largely composed of $\mathrm{SiO}_{2}$ which can form a network, and of $\mathrm{Al}_{2} \mathrm{O}_{3}$ as an intermediate oxide. The amount of network modifier was less than 14.7 mass $\%$. The chemical composition of the glassy phase showed a tendency that $\mathrm{Al}_{2} \mathrm{O}_{3}$ increased rather than $\mathrm{SiO}_{2}$ from the first hopper toward the third hopper.

\section{References}

1) Lee, S. H., Sakai, E., Daimon, M. and Bang, W. K., Cem. Concr. Res., Vol. 29, pp. 1791-1797 (1999).

2) Lee, S. H., Sakai, E., Watanabe, K., Yanagizawa, T. and Daimon, M., J. Soc. Mater. Sci. Japan, Vol. 48, pp. 837-842 (1999) [in Japanese].

3) Hemming, R. T. and Berry, E. E., Mater. Res. Soc. Symp. Proc., Vol. 113, pp. 3-38 (1988).

4) Joshi, R. C. and Rosaver, E. A., Am. Ceram. Soc. Bull., Vol. 52, pp. 456-461 (1973).

5) Sersale, R., Proc. 7th. Int. Cong. on Chem. of Cem., Paris, Vol. 1, pp. IV 1/3-1/18 (1980)

6) McCarthy, G. J., Johansen, D. M., Steinwand, S. J. and Thedchanamoorthy, A., Adv. X-ray Anal., Vol. 31, pp. 331-342 (1988).

7) McCarthy, G. J., Mater. Res. Soc. Symp. Proc., Vol. 113, pp. 75-86 (1988).

8) Nagataki, S., Ohga, H. and Nakamura, T., Proc. of the Japan Conc. Inst., Vol. 7, pp. 197-200 (1985) [in Japanese].

9) Roode, M., Douglas, E. and Hemming, R. T., Cem. Cocr. Res., Vol. 17, pp. 183-197 (1987).

10) Alexanders, L. and Klug, H. P., Anal. Chem., Vol. 20, pp. 886-889 (1948).

11) Hagino, Y., Hashizume, G. and Takashima, S., Japan Analyst, Vol. 5, pp. 91-95 (1956) [in Japanese].

12) Kummi, D. and Levenspiel, O., "Fludization Engineering," 2nd ed., Butterworth-Heinemann, Boston (1991) pp. 68-75.

13) MacCarthy, G. J. and Solem, J. K., Adv. X-ray Anal., Vol. 34, pp. 387-394 (1991).

14) Levin, E. M., Robbins, C. R. and McMurdie, H. F., "Phase Diagrams for Ceramists," Am. Ceram. Soc., Columbus (1964) OH: Fig. 630

15) Diamond, S., Cem. Concr. Res., Vol. 13, pp. 459-464 (1983).

16) Scholze, H., "Glas; Natur, Struktur, Eigenschaften," Dritte Auflage Springer-Verlag (1988) pp. 299-300. 